\title{
PPAR-alpha dependent regulation of vanin-1 mediates hepatic lipid metabolism
}

Citation for published version (APA):

van Diepen, J. A., Jansen, P. A., Ballak, D. B., Hijmans, A., Hooiveld, G. J., Rommelaere, S., Galland, F., Naquet, P., Rutjes, F. P., Mensink, R. P., Schrauwen, P., Tack, C. J., Netea, M. G., Kersten, S., Schalkwijk, J., \& Stienstra, R. (2014). PPAR-alpha dependent regulation of vanin-1 mediates hepatic lipid metabolism. Journal of Hepatology, 61(2), 366-372. https://doi.org/10.1016/j.jhep.2014.04.013

Document status and date:

Published: 01/08/2014

DOI:

10.1016/j.jhep.2014.04.013

Document Version:

Publisher's PDF, also known as Version of record

Document license:

Taverne

Please check the document version of this publication:

- A submitted manuscript is the version of the article upon submission and before peer-review. There can be important differences between the submitted version and the official published version of record.

People interested in the research are advised to contact the author for the final version of the publication, or visit the DOI to the publisher's website.

- The final author version and the galley proof are versions of the publication after peer review.

- The final published version features the final layout of the paper including the volume, issue and page numbers.

Link to publication

\footnotetext{
General rights rights.

- You may freely distribute the URL identifying the publication in the public portal. please follow below link for the End User Agreement:

www.umlib.nl/taverne-license

Take down policy

If you believe that this document breaches copyright please contact us at:

repository@maastrichtuniversity.nl

providing details and we will investigate your claim.
}

Copyright and moral rights for the publications made accessible in the public portal are retained by the authors and/or other copyright owners and it is a condition of accessing publications that users recognise and abide by the legal requirements associated with these

- Users may download and print one copy of any publication from the public portal for the purpose of private study or research.

- You may not further distribute the material or use it for any profit-making activity or commercial gain

If the publication is distributed under the terms of Article $25 \mathrm{fa}$ of the Dutch Copyright Act, indicated by the "Taverne" license above, 


\title{
PPAR-alpha dependent regulation of vanin-1 mediates hepatic lipid metabolism
}

\author{
Janna A. van Diepen ${ }^{1, * \dagger}$, Patrick A. Jansen ${ }^{2,}$, Dov B. Ballak ${ }^{1}$, Anneke Hijmans ${ }^{1}$, Guido J. Hooiveld ${ }^{3}$, \\ Samuel Rommelaere ${ }^{4,5,6}$, Franck Galland ${ }^{4,5,6}$, Philippe Naquet ${ }^{4,5,6}$, Floris P.J.T. Rutjes ${ }^{7}$, \\ Ronald P. Mensink ${ }^{8}$, Patrick Schrauwen ${ }^{8}$, Cees J. Tack ${ }^{1}$, Mihai G. Netea ${ }^{1}$, Sander Kersten ${ }^{3}$, \\ Joost Schalkwijk ${ }^{2,}$, Rinke Stienstra ${ }^{1,3,}$
}

\begin{abstract}
${ }^{1}$ Department of Medicine, Radboud University Nijmegen Medical Centre, Nijmegen, The Netherlands; ${ }^{2}$ Nijmegen Center for Molecular Life Sciences, Radboud University Nijmegen Medical Centre, Nijmegen, The Netherlands; ${ }^{3}$ Nutrition, Metabolism and Genomics Group, Division of Human Nutrition, Wageningen University, Wageningen, The Netherlands; ${ }^{4}$ Centre d'Immunologie de Marseille-Luminy (CIML), Aix-Marseille University, UM2, Marseille, France; ${ }^{5}$ Institut National de la Santé et de la Recherche Médicale (INSERM), U1104, Marseille, France; ${ }^{6}$ Centre National de la Recherche Scientifique (CNRS), UMR7280, Marseille, France; ${ }^{7}$ Department of Synthetic Organic Chemistry, Institute for Molecules and Materials, Radboud University Nijmegen, The Netherlands; ${ }^{8}$ Department of Human Biology, NUTRIM School for Nutrition, Toxicology and Metabolism, Maastricht University Medical Center, Maastricht, The Netherlands
\end{abstract}

Background \& Aims: Peroxisome proliferator-activated receptor alpha $(P P A R \alpha)$ is a key regulator of hepatic fat oxidation that serves as an energy source during starvation. Vanin-1 has been described as a putative PPAR $\alpha$ target gene in liver, but its function in hepatic lipid metabolism is unknown.

Methods: We investigated the regulation of vanin-1, and total vanin activity, by PPAR $\alpha$ in mice and humans. Furthermore, the function of vanin-1 in the development of hepatic steatosis in response to starvation was examined in Vnn1 deficient mice, and in rats treated with an inhibitor of vanin activity.

Results: Liver microarray analyses reveals that Vnn1 is the most prominently regulated gene after modulation of PPAR $\alpha$ activity. In addition, activation of mouse PPAR $\alpha$ regulates hepatic- and plasma vanin activity. In humans, consistent with regulation by PPAR $\alpha$, plasma vanin activity increases in all subjects after prolonged fasting, as well as after treatment with the PPAR $\alpha$ agonist fenofibrate. In mice, absence of vanin-1 exacerbates the fasting-induced increase in hepatic triglyceride levels. Similarly, inhibition of vanin activity in rats induces accumulation of hepatic triglycerides upon fasting. Microarray analysis reveal that the absence of vanin-1 associates with gene sets involved in liver steatosis, and reduces pathways involved in oxidative stress and inflammation.

Conclusions: We show that hepatic vanin-1 is under extremely sensitive regulation by $\operatorname{PPAR} \alpha$ and that plasma vanin activity could serve as a readout of changes in PPAR $\alpha$ activity in human subjects. In addition, our data propose a role for vanin-1 in regulation of hepatic TG levels during fasting.

(c) 2014 European Association for the Study of the Liver. Published by Elsevier B.V. All rights reserved.

\section{Introduction}

Pantetheinase; Lipid; Fasting; Steatosis; Triglyceride; Fenofibrate.

Received 12 November 2013; received in revised form 18 February 2014; accepted 6 April 2014; available online 18 April 2014

* Corresponding author. Address: Radboud University Medical Center, Department of General Internal Medicine (463), Geert Grooteplein 8, 6525 GA Nijmegen, The Netherlands. Tel.: +31 24 3610244; fax: +31 243541734 .

E-mail address: Janna.vanDiepen@radboudumc.nl (J.A. van Diepen).

${ }^{\dagger}$ These authors contributed equally to this work.

* These authors share senior authorship.

Abbreviations: PPAR, Peroxisome proliferator-activated receptor; RXR, Retinoid X Receptor; VNN1, vanin-1; VNN2, vanin-2; VNN3, vanin-3; WT, wild-type; BMI, body mass index; Pan-AMC, pantothenate-7-amino-4-methylcoumarin; TG, Triglycerides; TC, total cholesterol; FFA, free fatty acids; KLF15, Kruppel-like factor 15; STAT3, signal transducer and activator of transcription 3; SP1, trans-acting transcription factor 1 ; $\mathrm{CBFB}$, core binding factor beta; $\mathrm{XBP} 1$, $\mathrm{x}$-box binding protein 1; NAFLD, non-alcoholic fatty liver disease; Pan-PNa, pantothenate-4-nitroanilide; $A b c d 2$, chemokine (C-C motif) ligand 17; Acadm, acyl-CoA dehydrogenase, medium chain; Acot1, acyl-CoA thioesterase 1; Acot2, acyl-CoA thioesterase 2; Acsl5, acyl-CoA synthetase long-chain family member 5; Ehhadh, enoyl-CoA hydratase/3-hydroxylacyl CoA dehydrogenase; NASH, non-alcoholic steatohepatitis (NASH).
The liver is the central organ in the body's response to starvation and switches from glucose oxidation and lipogenesis in the fed state, towards fatty acid oxidation and glucose production in the fasted state. Peroxisome proliferator-activated receptor alpha (PPAR $\alpha$ ) is a ligand-activated transcription factor that functions as the central regulator of hepatic lipid metabolism. Ligands for PPAR $\alpha$ include endogenous fatty acids and various eicosanoids, as well as fibrate drugs used for the treatment of dyslipidemia [1]. Consistent with a crucial role of PPAR $\alpha$ in the adaptive response to fasting, removal of the food provokes a severe metabolic phenotype in mice lacking PPAR $\alpha$ that includes hypoglycemia, hypothermia, hypoketonemia, and severe hepatic steatosis [2].

Over the past 20 years, multiple target genes of PPAR $\alpha$ have been identified that play a role in different aspects of hepatic lipid 
metabolism, including uptake, binding, and oxidation of fatty acids, ketogenesis, lipid droplet biology, and lipoprotein assembly and transport [3]. In addition, PPAR $\alpha$ has emerged as a crucial transcriptional regulator of numerous other metabolic processes including metabolism of glucose, cholesterol, bile acids, and amino acids [4-6]. Several different research groups have identified vanin-1 as an important PPAR $\alpha$-target gene [3,7-9] and showed that production of vanin-1 depends on PPAR $\alpha$ activity [7]. However, despite the observations that vanin-1 is highly expressed in the liver as compared to other tissues $[10,11]$, little is known about its actual role in hepatic lipid metabolism.

Vanin-1 is known as a glycosylphosphatidylinositol (GPI)anchored enzyme with pantetheinase activity catalyzing the hydrolysis of pantetheine into pantothenic acid (vitamin B5) and cysteamine. Vanin-1 is member of a larger vanin family, encoded by two mouse (Vnn1 and Vnn3) and three human (VNN1, VNN2, and VNN3) orthologous genes [12]. Functional studies indicated a role for vanins in inflammation, oxidative stress, and cell migration $[10,13,14]$. These effects of vanins are thought to be mediated via vanin-dependent cysteamine production [15]. By controlling the synthesis of pantothenic acid, the precursor for Coenzyme A, vanins may additionally play a role in fatty acid metabolism [15,16], although this remains to be established.

The aim of the current study was to characterize the regulation of vanin- 1 and total vanin (pantetheinase) activity by PPAR $\alpha$ in mice and especially in human subjects, as well as the function of vanin-1 during fasting-induced hepatic lipid metabolism. We show that vanin activity closely reflects PPAR $\alpha$ activity, and activation of PPAR $\alpha$ induced by fasting or fibrate treatment enhanced plasma vanin activity in humans. Moreover, our data show that vanin activity functions as a modulator of hepatic lipid homeostasis in the fasted state.

\section{Materials and methods}

Animals

Mice and rats were housed under standard conditions and experiments were approved by the institutional ethical committee on animal care and experimentation of Wageningen University (Wageningen) or Radboud University Medical Center (Nijmegen). PPAR $\alpha^{-1-}$ and wild-type (WT) mice (Sv129 background; 2-3 month-old) were euthanized in the fed state vs. 6-, 12- or $24 \mathrm{~h}$ of fasting, or after 5-days of $0.1 \%$ Wy14643 supplementation [17]. Vanin-1-1- $\left(\right.$ Vnn-1 $\left.1^{-1-}\right)$ mice and WT littermates ( $\mathrm{C57Bl} / 6 \mathrm{~J}$ background; 3-4-month old) were euthanized in the fed state vs. $24 \mathrm{~h}$ of fasting. Male Wistar rats (Harlan) weighing 150-200 g were given the pantetheinase inhibitor RR6 [18] via drinking water $(3 \mathrm{mg} / \mathrm{ml})$ for 4 days and fasted during the final $24 \mathrm{~h}$ of the treatment.

Human intervention trails

The study protocols of the intervention trials have been published elsewhere [19$21]$, details are described in the Supplementary materials and methods. Protocols were approved by the Medical Ethical Committee of Maastricht University Medical Centre. All subjects gave their written informed consent before the start of the study.

Cell culture

Primary rat and mouse hepatocytes were isolated and cultured as described before [22]. After overnight adherence to the cell culture plate, hepatocytes were treated with various ligands for $24 \mathrm{~h}$ and RNA was isolated.

\section{JOURNAL OF HEPATOLOGY}

Vanin activity assay

Vanin (pantetheinase) activity was determined in liver and plasma as described before $[18,23]$ and in the Supplementary materials and methods. Shortly, liver homogenates and plasma samples were diluted and incubated with pantothenate-7-amino-4-methylcoumarin (Pan-AMC; $10 \mu \mathrm{M}$ final concentration). Fluorescence was measured using a luminescence spectrometer (LS55, Perkin Elmer).

Plasma and hepatic lipid analysis

Plasma levels of TG, total cholesterol (TC), glucose (Liquicolor, Human $\mathrm{GmbH}$, Wiesbaden, Germany) and free fatty acids (FFA; NEFA-C WAKO chemicals, GmbH Neuss Germany) were determined enzymatically according to manufacturer's instructions. Lipids were extracted from livers as described in the Supplementary materials and methods.

RNA isolation, $q P C R$, and microarray analysis

Total RNA was isolated from livers and reverse transcribed for subsequent qPCR analysis. RNA from livers of fed and $24 \mathrm{~h}$ fasted $\mathrm{Vnn}-1^{-1-}$ and WT mice was used for microarray analysis. Details of RNA isolation, primer sequences, and microarray analysis can be found in the Supplementary materials and methods section.

Statistical analysis

Data are presented as means \pm SD. Statistical analyses were performed using Graphpad Prism 5.0. Statistical comparisons between 2-groups were calculated using a Student's $t$ test. Differences between 4-groups were tested with ANOVA followed by post hoc Bonferroni correction. For the human intervention studies, comparisons between two conditions (fed vs. fast; before vs. after fenofibrate treatment) were performed using the paired Student $t$ test. $p<0.05$ was regarded statistically significant.

\section{Results}

Hepatic vanin activity is highly regulated by PPAR $\alpha$

Microarray studies were performed on livers of WT mice treated with PPAR $\alpha$ agonist Wy14643 vs. control for 5-days [17], revealing that the gene encoding vanin-1 was the most significantly induced gene by Wy14643 in WT mice (+90-fold; Fig. 1A). Moreover, microarray analysis of livers from $24 \mathrm{~h}$ fasted WT and $P P A R \alpha^{-1-}$ mice identified Vnn1 as the most strongly repressed gene in PPAR $\alpha^{-1-}$ mice in the fasted state $(-712$-fold; Fig. 1B). Similarly, vanin-3 mRNA was upregulated by Wy14643 treatment (+1.8-fold; Fig. 1C), and downregulated in fasted $P P A R \alpha^{-1-}$ compared to WT mice (-9.5-fold; Fig. 1D), although to a lesser extent than vanin-1. The activation of Vnn1 expression by PPAR $\alpha$ is a direct effect within hepatocytes, since Wy14643 induced an increase of Vnn1 in primary hepatocytes of WT mice. Moreover, this increase was absent in primary hepatocytes of $P P A R \alpha^{-1-}$ mice (Supplementary Fig. 1A). Additionally, stimulation of human hepatocytes with the PPAR $\alpha$-agonist GW7647 led to a dose-dependent increase in vnn1 gene expression (Supplementary Fig. 2). Finally, stimulation of cells with PPAR $\gamma$ agonist Rosiglitazone (Supplementary Fig. 1B) or RXR agonists LG1069, 9cRA, and atRA (Supplementary Fig. 3) mildly induced Vnn1 expression as compared to PPAR $\alpha$ agonists Wy14643 or fenofibrate.

Using a pantetheinase (vanin) activity assay that determines vanin- 1 activity and potentially activity of vanin-3 [7,23], we found that PPAR $\alpha$ not only regulates vanin-1 and vanin-3 mRNA expression, but also controls hepatic vanin enzymatic activity. Treatment of mice with Wy14643 induced activation of vanin 


\section{Research Article}

A

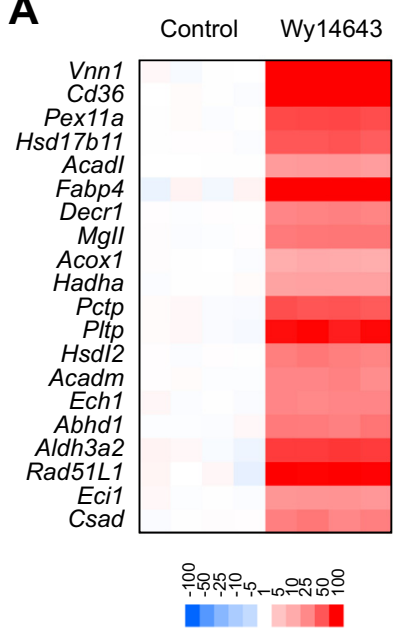

C

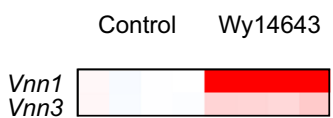

B

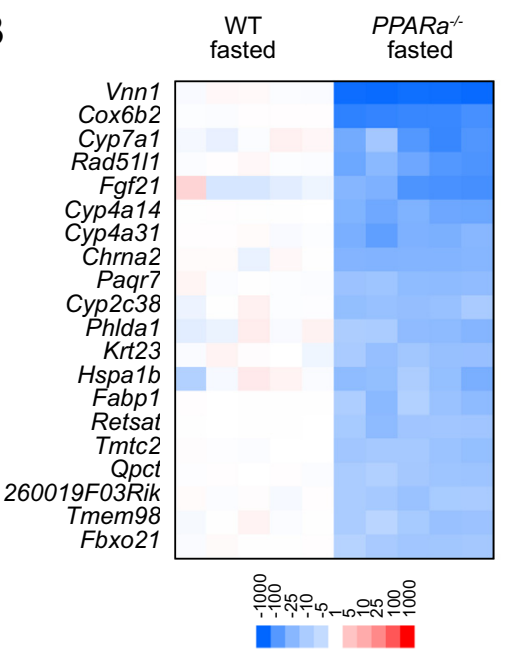

D

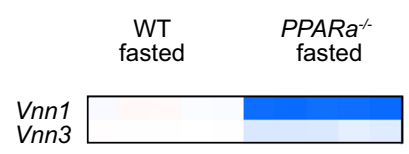

E

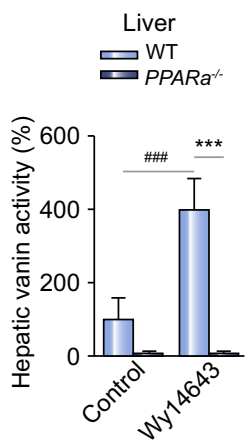

G

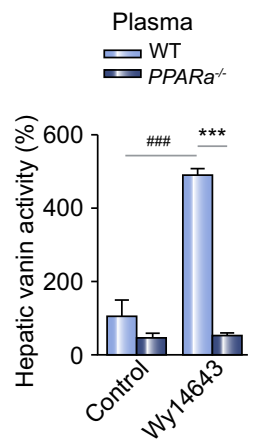

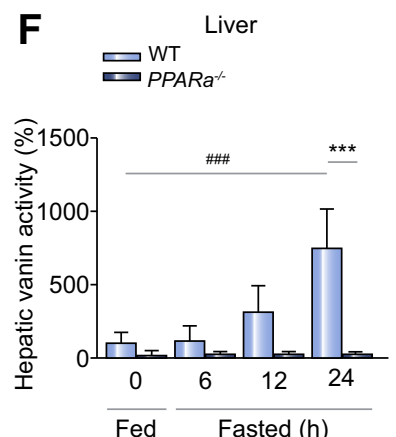

H

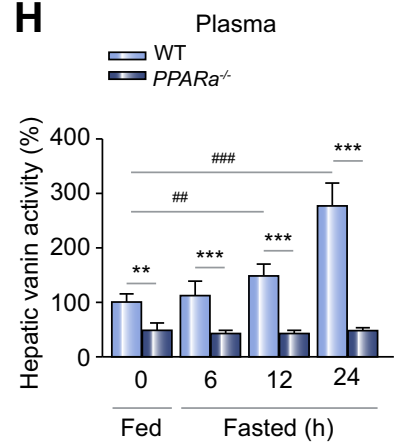

Fig. 1. Hepatic Vnn1 expression and enzymatic vanin activity are regulated by PPAR $\alpha$. PPAR $\alpha^{-1-} v s$. wild-type (WT) mice were treated with Wy-14643 for 5 days $(n=4-5)$ or fasted for 6,12 or $24 \mathrm{~h}(\mathrm{n}=5)$. Heat maps of liver show the top-20 of upregulated genes (A) and Vnn1 vs. Vnn3 (C) in Wy-14643 treated mice, and the top-20 of downregulated genes (B) and Vnn1 vs. Vnn3 (D) in fasted mice, (E and G) Vanin activity in liver (E) and plasma (G) of Wy-14643 treated mice. (F and H) Vanin activity in livers (F) and plasma (H) of fed vs. fasted mice. Values are means \pm SD. ${ }^{*} p<0.05 ;{ }^{* *} p<0.01 ;{ }^{* * *} p<0.001$ vs. WT mice and ${ }^{\# \#} p<0.01$; \#\#\# $p<0.001 v$ s. control.

activity (4-fold; $p<0.001$; Fig. 1E). Similarly, fasting caused a time-dependent upregulation of hepatic vanin activity up to 8 -fold ( $p<0.001$; Fig. 1F). Vanin activity was virtually undetectable in $P P A R \alpha^{-1-}$ mice, suggesting that hepatic vanin-1 activity, and potentially vanin-3 activity, is highly regulated by and fully dependent on PPAR $\alpha$ activation. Subsequent analysis revealed plasma vanin activity was increased to a similar extent as hepatic vanin activity upon activation of PPAR $\alpha$ using Wy14643 (5-fold; $p<0.001$; Fig. 1G) and fasting (up to 3-fold; $p<0.001$; Fig. $1 \mathrm{H}$ ). The strong reduction in plasma vanin activity in $P P A R \alpha^{-1-}$ mice (Fig. 2C and D) has recently been reported [7] and shows that PPAR $\alpha$ not only regulates hepatic vanin activity, but also strongly contributes to plasma vanin activity.

\section{Human plasma vanin activity increases upon PPAR activation}

Since plasma vanin activity is highly regulated by PPAR $\alpha$ activity in mice, we evaluated whether plasma vanin activity may reflect PPAR $\alpha$ activity in human subjects. First, plasma vanin activity was determined in subjects that were in fed state, or had fasted for $60 \mathrm{~h}$. Fig. 2A shows that basal plasma vanin activity levels showed marked inter-individual variation. However, $60 \mathrm{~h}$ of fasting raised plasma vanin activity in each individual by at least $10 \%$, with a mean increase of $33 \%(p<0.001$; Fig. 2 A). To reveal whether plasma vanin activity in human subjects indeed reflects PPAR $\alpha$ activation, vanin activity was determined in human subjects that were part of two fenofibrate intervention trials. First, vanin activity was increased significantly by fenofibrate treatment in all patients with type 2 diabetes after 3 months of treatment with the PPAR $\alpha$ agonist fenofibrate ( $200 \mathrm{mg} /$ day) (+23\%,
A

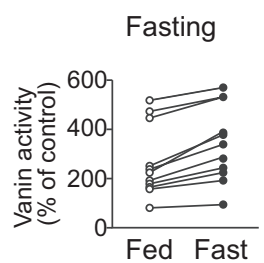

C

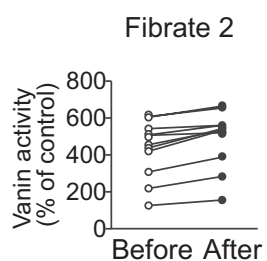

B Fibrate 1

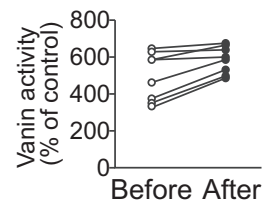

D Placebo

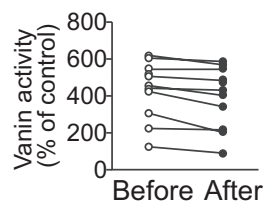

Fig. 2. Human plasma vanin activity increases upon PPAR $\alpha$ activation. (A) Vanin activity in plasma of (A) 12 healthy male subjects after a $60 \mathrm{~h}$ normal fed condition or after a $60 \mathrm{~h}$ fast, (B) 8 female patients with type 2 diabetes before and after treatment with fenofibrate for 3 months ( $200 \mathrm{mg} / \mathrm{d}$ ), (C and D) 11 obese subjects before and after treatment with fenofibrate (C) or placebo (D) for 6 weeks $(200 \mathrm{mg} /$ day $)$. Values are means \pm SD. ${ }^{* *} p<0.01$; ${ }^{* * *} p<0.001$

$p<0.01$; Fig. 2B). Second, vanin activity was determined in obese subjects before and after 6 weeks of treatment with fenofibrate $(200 \mathrm{mg} /$ day) and placebo control. Again, vanin activity was increased upon fenofibrate treatment $(+16 \%, p<0.001$; Fig. $2 \mathrm{C})$, but not in placebo treated subjects, which actually showed a reduction in vanin activity over time $(-10 \%, p<0.01$; Fig. 2D). These data clearly demonstrate that plasma vanin activity is 


\section{JOURNAL OF HEPATOLOGY}

increased by PPAR $\alpha$ activation in humans and suggest that plasma vanin activity could serve as a marker for (a change in) PPAR $\alpha$ activity.

Vanin-1 deficiency increases hepatic steatosis during starvation in mice

PPAR $\alpha$ is a critical regulator of hepatic lipid metabolism in response to starvation. The strong regulation of vanin- 1 by PPAR $\alpha$ therefore suggests a potential role of vanin-1 in hepatic lipid metabolism. To explore whether vanin- 1 affects the development of fasting-induced hepatic steatosis, hepatic lipid accumulation was evaluated in WT and $V n n 1^{-1-}$ mice. Oil-Red-O staining showed that vanin-1 deficiency caused an increased accumulation of lipids in $24 \mathrm{~h}$ fasted livers (Fig. 3A), which was mirrored by increased hepatic TG levels (Fig. 3B). In contrast, vanin-1 deficiency did not affect fed, or $24 \mathrm{~h}$ fasted plasma levels of TG (Fig. 3C), total cholesterol (TC; Fig. 3D), free fatty acids (FFA; Fig. 3E) or glucose levels (Supplementary Fig. 4).

Inhibition of total vanin activity increases hepatic steatosis during starvation in rats

We recently developed a novel pantetheine analog (RR6) that acts as a selective competitive vanin inhibitor at nanomolar concentration. This compound showed excellent pharmacodynamics in rats, but less so in mice, and caused a complete inhibition of plasma vanin activity [18]. We evaluated whether short-term inhibition of total vanin activity in rats would similarly induce fasting-induced hepatic steatosis as vanin-1 deficiency in mice. Therefore, rats were treated with RR6 in the drinking water $(50 \mathrm{mg} / \mathrm{kg}$ ) for 4 days and fasted for $24 \mathrm{~h}$. Consistent with the effects of vanin-1 deficiency in mice, inhibition of vanin activity by RR6 treatment increased hepatic steatosis in $24 \mathrm{~h}$ fasted rats as determined by an increased liver weight $(6.41 \pm 0.18 v s$. $6.88 \pm 0.22 ; p<0.001$ ), Oil-Red-O staining (Fig. $3 F$ ) and TG concentrations (Fig. 3G).

Hepatic pathways affected by vanin-1 deficiency during starvation

To further identify the function of vanin-1 in the liver during the fasting response, we evaluated relevant pathways downstream of vanin-1 using microarray analyses in livers of $24 \mathrm{~h}$ fasted $V n n 1^{-1-}$ and WT mice. These analysis revealed that 857 genes were differentially expressed $(p<0.05)$ in $V n n 1^{-1-}$ mice, of which 320 were repressed and 437 increased. Since vanin-1 appears such an important target gene of PPAR $\alpha$, and both PPAR $\alpha^{-1-}$ and $V n n 1^{-1-}$ mice develop hepatic steatosis in response to fasting, we compared the microarray of $V n n 1^{-1-} v s$. WT mice with the microarray of $P P A R \alpha^{-1-} v s$. WT mice after $24 \mathrm{~h}$ of fasting. Surprisingly, although 1077 genes were found to depend on PPAR $\alpha$ and 978 genes on vanin-1, only 71 of these genes were overlapping. Indeed, the top 150 most up- and downregulated genes in $V n n 1^{-1-}$ mice did show little overlap with their change in PPAR $\alpha^{-1-}$ mice (Supplementary Table $1 \mathrm{~A}$ and $\mathrm{B}$ ).

To investigate the function of vanin-1 in the hepatic fasting response, we evaluated pathways specifically influenced by vanin-1 deficiency. Therefore, a contrast comprising all 4 experimental groups (WT-fed compared to WT-fasted vs. Vnn1 ${ }^{-1-}$-fed compared to $V n n 1^{-1-}$-fasted) was tested for significance in the linear model to identify a robust set of genes that responded
A

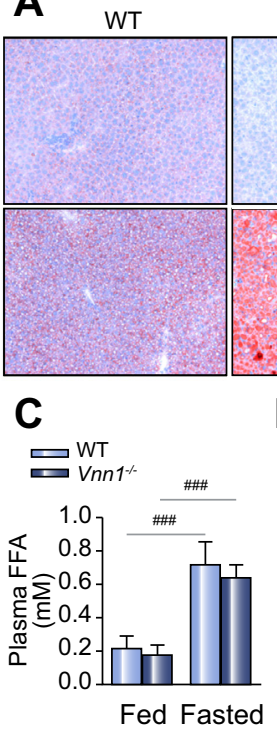

$V n n 1^{-}$

B

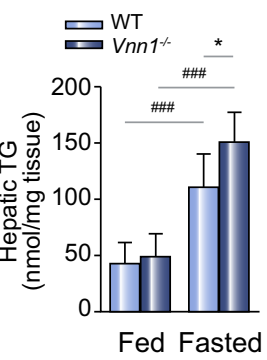

D

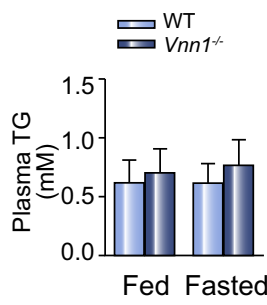

$\mathbf{E}$

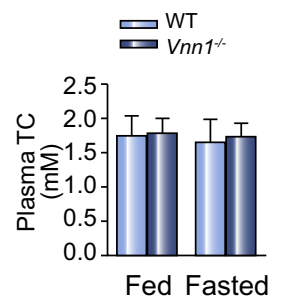

G

$\mathbf{F}$
Control

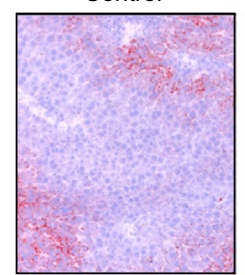

RR6

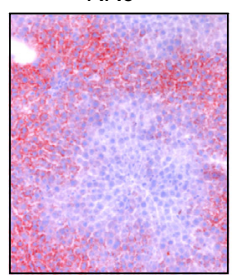

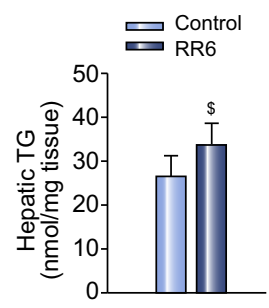

Fig. 3. Vanin-1 deficiency and inhibition of vanin activity aggravates hepatic steatosis during starvation. Vanin- $1^{-I^{-}}\left(V n n 1^{-1-}\right)$ and wild-type (WT) mice $(n=7)$ were fed or $24 \mathrm{~h}$ fasted and livers were isolated. Depicted are hepatic triglyceride (TG) levels (A), Oil Red O staining of representative liver sections (B), plasma free fatty acids (FFA) (C), TG (D) and total cholesterol (TC) (E). Rats were administered with the vanin inhibitor RR6 in drinking water for 4 days and fasted for $24 \mathrm{~h}(\mathrm{n}=7)$. Depicted are Oil Red O staining of representative liver sections $(\mathrm{F})$ and hepatic triglyceride (TG) levels $(G)$. Values are means \pm SD. ${ }^{*} p<0.05 v s$. WT mice, ${ }^{\$} p<0.05$ vs. control condition; ${ }^{\# \#} p<0.001$ vs. fed condition.

differentially to $24 \mathrm{~h}$ of fasting in WT and $V n n 1^{-1-}$ mice (Fig. 4A). Ingenuity analysis revealed that gene sets affected by vanin-1 deficiency were most significantly linked to an increase in hepatic steatosis, in accordance with the observed increase in hepatic TG accumulation in $V n n 1^{-1-}$ mice in response to fasting (Fig. 4B). In addition, gene sets involved in several other diseases or clinical pathology endpoints were significantly affected in $V n n 1^{-1-}$ mice, such as glutathione depletion, TR/RXR activation, liver hepatitis, and oxidative stress, suggesting an impact of vanin-1 on these hepatic pathologies. For better understanding of signaling pathways that may be responsible for the changes in hepatic gene expression upon vanin-1 deficiency during the fasting response, ingenuity upstream regulator analysis were used. These analysis predicted that transcription factors known to regulate gene sets involved in (lipid) metabolism (PPAR $\alpha, P P A R \gamma$, and KLF15), inflammation/immunity, cell differentiation and hematopoiesis (STAT3, SP1, and CBFB), and oxidative stress (XBP1) were significantly changed in livers of $V n n 1^{-1-}$ mice (Fig. 4C). Specifically, PPAR $\alpha, P P A R \gamma, C B F B$, and KLF15 were predicted to be activated, while XBP1, SP1, and STAT3 were predicted 


\section{Research Article}

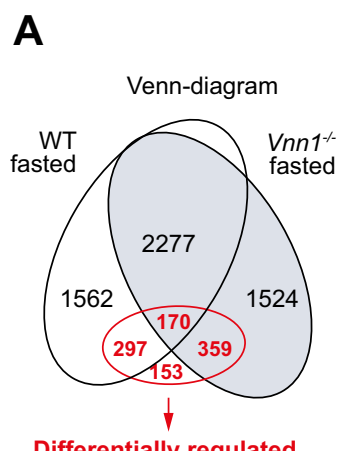

Differentially regulated
B $\rightleftharpoons$ Downregulated Upregulated
No overlap with dataset

$\longrightarrow \square-\log (p$ value $)$

\section{Increases liver steatosis}

Glutathione depletion - phase II reaction

TR/RXR activation

Increases liver hepatitis

Oxidative stress

LXR/RXR activation

Mechanisms of gene regulation by peroxisome proliferators via PPAR $\alpha$

p53 signaling

Genes associated with chronic allograft nephropathy (human)

Increases transmembrane potential of mitochondria and mitochondrial membrane
Percentage $(\%)$

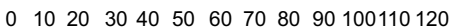

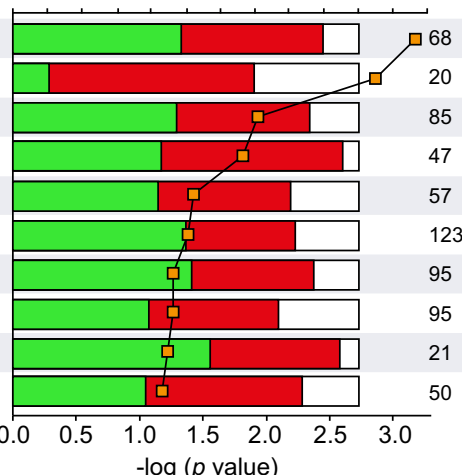

C

D

\begin{tabular}{|c|c|c|c|c|}
\hline $\begin{array}{l}\text { Upstream } \\
\text { regulator }\end{array}$ & $\begin{array}{l}\text { Predicted } \\
\text { activation state }\end{array}$ & $\begin{array}{l}\text { Activation } \\
\text { Z-score }\end{array}$ & $\begin{array}{l}p \text { value } \\
\text { overlap }\end{array}$ & Target molecule in dataset \\
\hline PPARA & Activated & 4.1 & 2.48E-07 & $\begin{array}{l}\text { ABCD2, ACACA, ACADM, ACOT1, ACOT2, ACSL5, } \\
\text { APOA2, ARG1, C1R, C1S, C2, CD36, CDKN2C, } \\
\text { CHRNA2, CIDEC, CTH, CTSE, DBI, EHHADH, GNMT, } \\
\text { GSTM3, HSD17B11, KRT23, LAMB3, LPCAT3, LY6D, } \\
\text { MGST3, Mup1, MVK, PAH, PBLD, PDK4, PLIN2, PLTP, } \\
\text { SARDH, SELENBP1, TMEM98, VNN1 }\end{array}$ \\
\hline CBFB & Activated & 2.53 & $2.28 \mathrm{E}-04$ & $\begin{array}{l}\text { GPLD1, ICAM1, KCNK5, PRRG1, RGS1, RUNX1, } \\
\text { RUNX3, SLC25A19, STAT4, TNFAIP8L2 }\end{array}$ \\
\hline PPARG & Activated & 2.826 & $1.12 \mathrm{E}-02$ & $\begin{array}{l}\text { ACACA, ACADM, ACSL5, ATP6V1D, CD36, CIDEC, } \\
\text { CRAT, EHHADH, FN1, HES1, ICAM1, LAMB3, LY6D, } \\
\text { NDRG1, NR4A1, PDK4, PLIN2, PRODH, PTGES, } \\
\text { PYGL, SORBS1, VNN1 }\end{array}$ \\
\hline KLF15 & Activated & 2.224 & 1.37E-02 & ACADM, ACOT1, CD36, EHHADH, PDK4 \\
\hline XBP1 & Inhibited & -2.625 & $4.81 \mathrm{E}-03$ & $\begin{array}{l}\text { APBB2, ATF6B, DDOST, EDEM1, EDEM2, FN1, } \\
\text { ICAM1, MGAT2, RPN2, SEC63, SRP19, SRP68, SRP9, } \\
\text { SSR3, TRAM1, TXNDC11 }\end{array}$ \\
\hline SP1 & Inhibited & -2.11 & 6.06E-02 & $\begin{array}{l}\text { ABHD2, ADCY4, AR, B4GALT5, CCND2, CTH, } \\
\text { CXCL10, F2R, FN1, GDF15, HAS2, MYCN, NDRG1, } \\
\text { POLB, PRKCA, SLC22A, SLC2A12, TRIB1, TXNRD1 }\end{array}$ \\
\hline STAT3 & Inhibited & -2.033 & 7.67E-02 & $\begin{array}{l}\text { ARG1, CCL3L1/CCL3L3, CLL4, CLN6, CXCL10, FN1, } \\
\text { HAS2, ICAM1, IKBKE, PEX1, PSMB8, Serpina3K, } \\
\text { SMAD9, SOCS3, TNFRSF1B }\end{array}$ \\
\hline
\end{tabular}

Fig. 4. Hepatic pathways affected by vanin-1 deficiency during starvation. Ingenuity analysis on genes that respond differentially to $24 \mathrm{~h}$ fasting in WT $v s$. Vnn $1^{-1-}$ mice $(n=4-5)$. (A) Venn diagram of genes selected for Ingenuity analysis. (B) Pathologies associated with selected genes, line reflects $-\log (p$ value). Bars reflect percentage of genes within a pathology/disease that are downregulated (green), upregulated (red), or do not show overlap with the dataset (white). (C) Common upstream regulators of selected genes (see Supplementary Fig. S5 for enlargement). Figure represents upregulated (red label) or downregulated (green label) genes, and associated upstream regulators, predicted to be activated (orange) or inhibited (blue). (D) Upstream regulators with significantly regulated target genes in the dataset.

to be inhibited. A complete list of genes affected by vanin-1 deficiency and under control of these transcription factors can be found in Fig. 4D.

\section{Discussion}

Since 2002, vanin-1 has emerged as a gene that is robustly activated in liver by PPAR $\alpha$ agonists, such as Wy14643, fenofibrate, and clofibrate $[3,8,9]$, and functional PPRE sites have recently been identified in the Vnn1 promoter [7]. Despite these observations, the regulation of hepatic vanin activity by PPAR $\alpha$ and the functional implications of PPAR $\alpha$-dependent regulation of vanin-1 have never been evaluated. Our data reveal that vanin1 is one of the most prominent PPAR $\alpha$-dependent regulated genes. We also show that vanin-3 is regulated by PPAR $\alpha$, although to a lesser extent, and that total hepatic vanin-1 activity, and possibly activity of vanin-3, is under strict control of PPAR $\alpha$. The observation that vanin-1 is membrane-bound via a GPI anchor, while vanin-3 is not, has led to the hypothesis that vanin-3 can be secreted and determines plasma vanin activity [12]. However, it has recently been revealed that vanin-1 can be secreted as a soluble Vnn1 isoform [7] and is expressed on microparticles that are secreted by hepatocytes into the circulation [24].

In humans, our data show a high inter-individual variation for plasma vanin activity, but within each subject plasma vanin activity appeared very stable over time. The VNN1 promoter contains methylation-sensitive SNPs, which makes the gene sensitive for allele-specific DNA methylation [25] and may allow for a large (epi)genetic component that determines vanin activity within a subject. We show that plasma vanin activity increased in all subjects that were fasted, or treated with fibrate drugs. Since fasting is known to increase hepatic steatosis [2], while fibrates may reduce hepatic steatosis [26], our data suggest that plasma vanin 


\section{JOURNAL OF HEPATOLOGY}

activity levels reflect PPAR $\alpha$ activation rather than hepatic steatosis. Furthermore, the stable vanin activity levels over time imply that plasma vanin activity could possibly be used as a marker for (a change in) PPAR $\alpha$ activation within a given individual. It must be noted that in human blood, the expression of VNN2 is much higher compared to VNN1 [10], which may explain the relatively small increase in total plasma vanin activity in human subjects upon fasting or specific PPAR $\alpha$ activation, compared to mice. Therefore, also based on our observation that the regulation of vanin-1 by PPAR $\alpha$ is much stronger than the regulation of vanin-3, we suggest that an assay to specifically determine plasma vanin-1 may even be a more sensitive read-out of PPAR $\alpha$ activation. In addition to the role of PPAR $\alpha$, levels of PPAR $\gamma$ are known to be increased in a steatotic liver [27]. Noticeably, absence of PPAR $\alpha$ leads to an upregulation of hepatic PPAR $\gamma$ levels in the liver upon a HFD-intervention [28]. Activation of PPAR $\gamma$ by TZDs is known to reduce the levels of hepatic steatosis [27]. Part of this effect may be accomplished by direct regulation of various hepatic PPAR $\alpha$-target genes by PPAR $\gamma$ during the presence of steatosis [28]. Hence, one may hypothesize that during specific conditions, e.g., the presence of steatosis, enhanced hepatic levels of PPAR $\gamma$ may regulate vnn1 expression as well.

Although vanin-1 is known to recycle pantothenic acid and has been described as a PPAR $\alpha$ target gene, the role of vanin activity in hepatic metabolic processes has so far never been evaluated. Recent studies show strongly increased vanin-1 expression in murine steatotic livers $[29,30]$, prompting the authors to hypothesize a causal role for vanin-1 in the progression of steatosis [30]. On the contrary, our current data show that the presence of vanin-1 does actually protect against the development of steatosis, induced by prolonged starvation. This suggests that the previously observed relation between steatosis and vanin-1 expression may rather be explained by enhanced activation of PPAR $\alpha$ and subsequent transcription of its target genes in steatotic livers [28].

In the current study, we use prolonged fasting to study the development of steatosis and show that vanin-1 expression prevents excessive accumulation of TGs in the liver. Whether vanin1 may similarly protect against fatty liver development induced by HFD-feeding or obesity needs to be evaluated in future studies. Cysteamine, which is generated by vanin activity, is currently under evaluation as a treatment for non-alcoholic fatty liver disease (NAFLD) in patients [31]. Since vanin-1 is the main provider of cysteamine to tissues, and $V n n 1^{-1-}$ mice are known to lack detectable amounts of cysteamine in their tissues [11], our data would suggest that (1) the protection of vanin-1 against steatosis may at least partly be mediated via cysteamine, and (2) activation of vanin activity could be an alternative for cysteamine treatment in patients with NAFLD.

Our data show no effect of vanin-1 deficiency on plasma TG, cholesterol, FFA or glucose levels in mice. In contrast, we recently found that inhibition of vanin activity in fasted rats increased plasma FFA and reduced plasma cholesterol levels [18]. Since inhibition of total vanin activity in rats also reduces vanin-3 activity, this may point towards a role of vanin-3 in the mobilization and/or conversion of lipids. No compensatory upregulation of hepatic vanin-3 mRNA levels in Vnn $1^{-1-}$ mice was observed (Supplementary Fig. 6), but the considerable level of vanin activity in $V n n 1^{-1-}$ mice, as detected by Rommelaere et al. [7], suggests that residual vanin-3 activity could possibly explain the relatively mild phenotype of the $V n n 1^{-1-}$ mice with respect to plasma lipid levels. Alternatively, differences between both experiments may be explained by species differences or compensatory mechanisms due to life-long deficiency of vanin-1 in mice $v s$. short-term inhibition of vanin activity in rats. Pantethine, the stable disulfide of pantetheine and substrate for vanin activity, is known as a natural compound with hypolipidemic effects [32], which may be mediated by increased cysteamine levels [33]. Future studies in hyperlipidemic mouse models will be needed to further elucidate whether vanin-1 or total vanin activity can directly affect plasma lipoprotein metabolism.

We show that absence of vanin-1 in mice and inhibition of vanin activity in rats both lead to increased TG hepatic accumulation in response to starvation. Microarray analysis reveals that this occurs despite activation of the transcriptional regulators PPAR $\alpha$ and KLF-15, and many of its target genes known to be involved in FA oxidation (i.e., Abcd2, Acadm, Acot1, Acot2, Acsl5, and $E h h a d h$ ). Besides PPAR $\alpha$, our analysis predicts increased activation of hepatic PPAR $\gamma$ activity in absence of vanin-1. Of course, both PPARs recognize similar DNA response elements and activation in fasted $V n n 1^{-1-}$ mice may result from increased availability of PPAR ligands (i.e., fatty acids) during steatosis. In addition, vanin-1 has shown to antagonize PPAR $\gamma$ activity, at least in epithelial cells [13] and a similar association in liver may also underlie the increased hepatic PPAR $\gamma$ activity in absence of vanin-1.

Several genes under control of XBP-1, a main regulator of oxidative stress, were downregulated in $V n n 1^{-1-}$ mice. Vanin-1 deficiency is known to enhance hepatic glutathione levels (secondary to the lack of tissue cysteamine [34]), which is an antioxidant that protects the tissue against reactive oxygen species. Our results are in line with the previous observation of reduced activation of pathways related to oxidative stress in livers of $V n n 1^{-1-}$ mice [35]. Besides oxidative stress, vanin-1 deficiency affected multiple genes involved in inflammation/immunity, predicting inhibition of the central inflammatory transcriptional regulator STAT3. A role for vanin-1 in immune responses has previously been reported, as $V n n 1^{-1-}$ mice display reduced immune cell activation during chronic intestinal inflammation, as well as a reduced proinflammatory macrophage phenotype in response to $C$. Burnetii $[13,36]$. Our data support a role for vanin-1 in the regulation of inflammatory pathways in liver and imply that gene sets affected by vanin-1 deficiency are involved in the development of steatohepatitis. Future studies in specific mouse models for non-alcoholic steatohepatitis (NASH) development may reveal whether vanin-1 indeed plays a role in the development of NASH.

In summary, we show that PPAR $\alpha$ is the regulator of hepatic vanin-1 expression and vanin activity. In addition, PPAR $\alpha$ activity strongly modulates plasma vanin activity, which therefore could be used as a marker for (a change in) PPAR $\alpha$ activity in humans. Finally, we show that vanin activity plays an important role in the prevention of steatosis development in response to fasting, and actions of vanin-1 in liver are linked to changes in inflammation and oxidative stress. This suggests that therapeutic strategies designed to enhance vanin activity may be beneficial for the treatment of hepatic steatosis or related diseases.

\section{Financial support}

This work was supported by a pre-seed grant of The Netherlands Genomics Initiative, grant nr 93611013. R.S. was supported by a grant from the Dutch Diabetes Research Foundation. 
Research Article

\section{Conflict of interest}

The authors who have taken part in this study declare that they do not have anything to disclose regarding funding or conflict of interest with respect to this manuscript.

\section{Acknowledgement}

The authors thank Ivonne M.J.J. van Vlijmen-Willems for excellent technical assistance and Pedro H.H. Hermkens for his contributions to the development of RR6.

\section{Supplementary data}

Supplementary data associated with this article can be found, in the online version, at http://dx.doi.org/10.1016/j.jhep.2014.04.013.

\section{References}

[1] Kliewer SA, Sundseth SS, Jones SA, Brown PJ, Wisely GB, Koble CS, et al. Fatty acids and eicosanoids regulate gene expression through direct interactions with peroxisome proliferator-activated receptors alpha and gamma. Proc Natl Acad Sci U S A 1997;94:4318-4323.

[2] Kersten S, Seydoux J, Peters JM, Gonzalez FJ, Desvergne B, Wahli W. Peroxisome proliferator-activated receptor alpha mediates the adaptive response to fasting. J Clin Invest 1999;103:1489-1498.

[3] Rakhshandehroo M, Knoch B, Muller M, Kersten S. Peroxisome proliferatoractivated receptor alpha target genes. PPAR Res 2010;2010:20 pages. Article ID 612089. http://dx.doi.org/10.1155/2010/612089.

[4] Kersten S, Mandard S, Escher P, Gonzalez FJ, Tafuri S, Desvergne B, et al. The peroxisome proliferator-activated receptor alpha regulates amino acid metabolism. FASEB J 2001;15:1971-1978.

[5] Guerre-Millo M, Rouault C, Poulain P, Andre J, Poitout V, Peters JM, et al PPAR-alpha-null mice are protected from high-fat diet-induced insulin resistance. Diabetes 2001;50:2809-2814.

[6] Li TG, Chiang JYL. Regulation of bile acid and cholesterol metabolism by PPARs. PPAR Res 2009;2009:15 pages. Article ID 501739. http://dx.doi.org $10.1155 / 2009 / 501739$

[7] Rommelaere S, Millet V, Gensollen T, Bourges C, Eeckhoute J, Hennuyer N, et al. PPARalpha regulates the production of serum Vanin-1 by liver. FEBS Lett 2013;587:3742-3748.

[8] Yamazaki K, Kuromitsu J, Tanaka I. Microarray analysis of gene expression changes in mouse liver induced by peroxisome proliferator activated receptor alpha agonists. Biochem Biophys Res Commun 2002;290:1114-1122.

[9] Moffit JS, Koza-Taylor PH, Holland RD, Thibodeau MS, Beger RD, Lawton MP et al. Differential gene expression in mouse liver associated with the hepatoprotective effect of clofibrate. Toxicol Appl Pharmacol 2007;222: 169-179.

[10] Jansen PAM, Kamsteeg M, Rodijk-Olthuis D, van Vlijmen-Willems IMJJ, de Jongh GJ, Bergers M, et al. Expression of the vanin gene family in normal and inflamed human skin: induction by proinflammatory cytokines. J Invest Dermatol 2009;129:2167-2174.

[11] Pitari G, Malergue F, Martin F, Philippe JM, Massucci MT, Chabret C, et al Pantetheinase activity of membrane-bound Vanin-1: lack of free cysteamine in tissues of Vanin-1 deficient mice. FEBS Lett 2000;483:149-154.

[12] Martin F, Malergue F, Pitari G, Philippe JM, Philips S, Chabret C, et al. Vanin genes are clustered (human 6q22-24 and mouse 10A2B1) and encode isoforms of pantetheinase ectoenzymes. Immunogenetics 2001;53:296-306.

[13] Berruyer C, Pouyet L, Millet V, Martin FM, LeGoffic A, Canonici A, et al. Vanin1 licenses inflammatory mediator production by gut epithelial cells and controls colitis by antagonizing peroxisome proliferator-activated receptor gamma activity. J Exp Med 2006;203:2817-2827.

[14] Sendo F, Araki Y. Regulation of leukocyte adherence and migration by glycosylphosphatidyl-inositol-anchored proteins. J Leukoc Biol 1999;66:369-374.
[15] Kaskow BJ, Proffitt JM, Blangero J, Moses EK, Abraham LJ. Diverse biological activities of the vascular non-inflammatory molecules - The Vanin pantetheinases (vol 417, pg 653, 2012). Biochem Biophys Res Commun 2012;422, 786-786.

[16] Daugherty M, Polanuyer B, Farrell M, Scholle M, Lykidis A, de Crecy-Lagard V, et al. Complete reconstitution of the human coenzyme A biosynthetic pathway via comparative genomics. J Biol Chem 2002;277:21431-21439.

[17] Rakhshandehroo M, Sanderson LM, Matilainen M, Stienstra R, Carlberg C, de Groot PJ, et al. Comprehensive analysis of palpha-dependent regulation of hepatic lipid metabolism by expression profiling. PPAR Res 2007;2007:13 pages. Article ID 26839. http://dx.doi.org/10.1155/2007/26839.

[18] Jansen PAM, van Diepen JA, Ritzen B, Zeeuwen PLJM, Cacciatore I, Cornacchia $C$, et al. Discovery of small molecule vanin inhibitors: new tools to study metabolism and disease. ACS Chem Biol 2013;8:530-534.

[19] Hoeks J, van Herpen NA, Mensink M, Moonen-Kornips E, van Beurden D, Hesselink MKC, et al. Prolonged fasting identifies skeletal muscle mitochondrial dysfunction as consequence rather than cause of human insulin resistance. Diabetes 2010;59:2117-2125.

[20] Bragt MCE, Mensink RP. Comparison of the effects of n-3 long chain polyunsaturated fatty acids and fenofibrate on markers of inflammation and vascular function, and on the serum lipoprotein profile in overweight and obese subjects. Nutr Metab Cardiovasc Dis 2012;22:966-973.

[21] Haluzik MM, Anderlova K, Dolezalova R, Adamikova A, Haluzikova D, Housova J, et al. Serum adipocyte fatty acid binding protein levels in patients with type 2 diabetes mellitus and obesity: the influence of fenofibrate treatment. Physiol Res 2009:58:93-99.

[22] Kuipers F, Jong MC, Lin Y, Eck M, Havinga R, Bloks V, et al. Impaired secretion of very low density lipoprotein-triglycerides by apolipoprotein E-deficient mouse hepatocytes. J Clin Invest 1997:100:2915-2922.

[23] Ruan BH, Cole DC, Wu P, Quazi A, Page K, Wright JF, et al. A fluorescent assay suitable for inhibitor screening and vanin tissue quantification. Anal Biochem 2010:399:284-292.

[24] Povero D, Eguchi A, Johnson C, Wree A, Lazic M, Parola M, et al. Hepatocytederived microparticles with a specific antigenic composition are released in blood during Nash development: implications for biomarkers development. J Hepatol 2013;58, S34-S34.

[25] Kerkel K, Spadola A, Yuan E, Kosek J, Jiang L, Hod E, et al. Genomic surveys by methylation-sensitive SNP analysis identify sequence-dependent allelespecific DNA methylation. Nat Genet 2008;40:904-908.

[26] Kostapanos MS, Kei A, Elisaf MS. Current role of fenofibrate in the prevention and management of non-alcoholic fatty liver disease. World J Hepatol 2013;5:470-478.

[27] Garcia-Ruiz I, Rodriguez-Juan C, Diaz-Sanjuan T, Martinez MA, Munoz-Yague T, Solis-Herruzo JA. Effects of rosiglitazone on the liver histology and mitochondrial function in ob/ob mice. Hepatology 2007;46:414-423.

[28] Patsouris D, Reddy JK, Muller M, Kersten S. Peroxisome proliferatoractivated receptor alpha mediates the effects of high-fat diet on hepatic gene expression. Endocrinology 2006;147:1508-1516.

[29] Kahle M, Horsch M, Fridrich B, Seelig A, Schultheiss J, Leonhardt J, et al. Phenotypic comparison of common mouse strains developing high-fat dietinduced hepatosteatosis. Mol Metab 2013:2:435-446.

[30] Motomura W, Yoshizaki T, Takahashi N, Kumei S, Mizukami Y, Jang SJ, et al. Analysis of vanin-1 upregulation and lipid accumulation in hepatocytes in response to a high-fat diet and free fatty acids. J Clin Biochem Nutr 2012:51:163-169.

[31] Besouw M, Masereeuw R, van den Heuvel L, Levtchenko E. Cysteamine: an old drug with new potential. Drug Discov Today 2013:18:785-792.

[32] Bocos C, Herrera E. Pantethine stimulates lipolysis in adipose tissue and inhibits cholesterol and fatty acid synthesis in liver and intestinal mucosa in the normolipidemic rat. Environ Toxicol Pharmacol 1998:6:59-66.

[33] Wittwer CT, Graves CP, Peterson MA, Jorgensen E, Wilson DE, Thoene JG, et al. Pantethine lipomodulation - evidence for cysteamine mediation in vitro and in vivo. Atherosclerosis 1987;68:41-49.

[34] Berruyer C, Martin FM, Castellano R, Macone A, Malergue F, Garrido-Urbani $\mathrm{S}$, et al. Vanin-1(-/-) mice exhibit a glutathione-mediated tissue resistance to oxidative stress. Mol Cell Biol 2004:24:7214-7224.

[35] Di Leandro L, Maras B, Schinina ME, Dupre S, Koutris I, Martin FM, et al. Cystamine restores GSTA3 levels in Vanin-1 null mice. Free Radic Biol Med 2008:44:1088-1096.

[36] Meghari S, Berruyer C, Lepidi H, Galland F, Naquet P, Mege JL. Vanin-1 controls granuloma formation and macrophage polarization in Coxiella burnetii infection. Eur J Immunol 2007;37:24-32. 